\title{
Amyloid peptide mixtures: self-assembly, hydrogelation, nematic ordering and catalysts in aldol reactions
}

Article

Published Version

Creative Commons: Attribution 4.0 (CC-BY)

Open Access

Pelin, J., Gerbelli, B., Edwards-Gayle, C. J. C., Aguilar, A., Castelletto, V., Hamley, I. W. and Alves, W. A. (2020) Amyloid peptide mixtures: self-assembly, hydrogelation, nematic ordering and catalysts in aldol reactions. Langmuir, 36 (11). pp. 2767-2774. ISSN 1520-5827 doi:

https://doi.org/10.1021/acs.langmuir.0c00198 Available at https://centaur.reading.ac.uk/89355/

It is advisable to refer to the publisher's version if you intend to cite from the work. See Guidance on citing.

To link to this article DOI: http://dx.doi.org/10.1021/acs.langmuir.0c00198

Publisher: American Chemical Society

All outputs in CentAUR are protected by Intellectual Property Rights law, including copyright law. Copyright and IPR is retained by the creators or other copyright holders. Terms and conditions for use of this material are defined in the End User Agreement. 


\section{CentAUR}

Central Archive at the University of Reading

Reading's research outputs online 


\title{
Amyloid Peptide Mixtures: Self-Assembly, Hydrogelation, Nematic Ordering, and Catalysts in Aldol Reactions
}

\author{
Juliane N. B. D. Pelin, Barbara B. Gerbelli, Charlotte J. C. Edwards-Gayle, Andrea M. Aguilar, \\ Valeria Castelletto, Ian W. Hamley,* and Wendel A. Alves*
}

Cite This: https://dx.doi.org/10.1021/acs.langmuir.0c00198

Read Online

ACCESS |

山ll Metrics \& More

回 Article Recommendations

S1 Supporting Information

ABSTRACT: Morphological, spectroscopic, and scattering studies of the self-assembly and aggregation of mixtures of $[\mathrm{RF}]_{4}$ and $\mathrm{P}[\mathrm{RF}]_{4}$ peptides (where $\mathrm{R}=$ arginine; $\mathrm{F}=$ phenylalanine; $\mathrm{P}=$ proline), in solution and as hydrogels, were performed to obtain information about polymorphism. CD data confirmed a $\beta$-sheet secondary structure in aqueous solution, and TEM images revealed nanofibers with diameters of $\sim 10 \mathrm{~nm}$ and micrometer lengths. SAXS curves were fitted using a mass fractal-component and a long cylinder shell form factor for the liquid samples, and only a long cylinder shell form factor for the gels. Increasing the $\mathrm{P}[\mathrm{RF}]_{4}$ content in the systems leads to a reduction in cylinder radius and

$[R F]_{4}$ and $P[R F]_{4}$
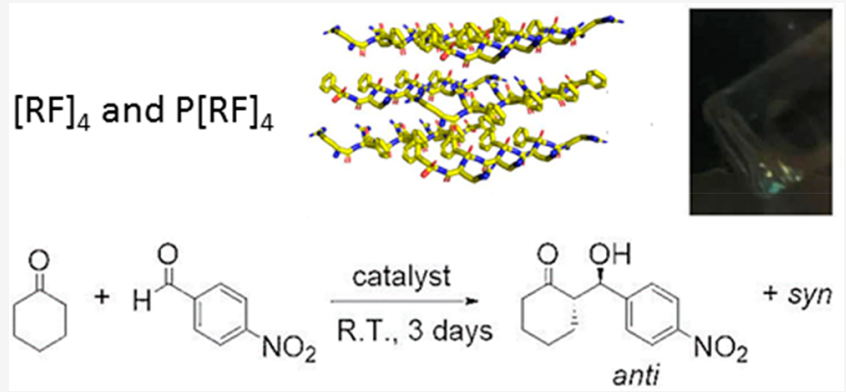
core scattering density, suggesting an increase in packing of the peptide molecules; however, the opposite effect is observed for the gels, where the scattering density is higher in the shell for the systems containing higher $\mathrm{P}[\mathrm{RF}]_{4}$ content. These compounds show potential as catalysts in the asymmetric aldol reactions, with cyclohexanone and $p$-nitrobenzaldehyde in aqueous media. A moderate conversion (36.9\%) and a good stereoselectivity (69:31) were observed for the system containing only $[\mathrm{RF}]_{4}$. With increasing $\mathrm{P}[\mathrm{RF}]_{4}$ content, a considerable decrease of the conversion was observed, suggesting differences in the self-assembly and packing factor. Rheological measurements were performed to determine the shear moduli for the soft gels.

\section{INTRODUCTION}

Over the last years, self-assembled amphiphilic oligopeptides systems have attracted strong interest due to their potential for bionanotechnological applications for new materials and in the development of diagnostic and therapeutic strategies, where protein and peptide aggregation is associated with disease. ${ }^{1-4}$ Peptide amphiphiles (PAs) are structures based on hydrophobic blocks such as lipid chains, and bioactive peptides, which correspond to the hydrophilic part. ${ }^{5,6}$ Among several promising uses, we can highlight the development of sensing devices, ${ }^{7}$ molecular carriers, ${ }^{8,9}$ and bioelectronics. ${ }^{10}$ Many advantages, especially the fast synthesis, functionalization capabilities, and relatively low cost, confirm the potential of these systems. $2,11-16$

One of the significant advantages of peptide amphiphiles as models for the aggregation process studies is their capability of self-assembly into distinct polymorphs. ${ }^{11,12,17}$ Thus, these systems are appropriate architectures to create biomimetic materials and establish interfaces with biological systems. The combination of amino acids with different molecular characteristics leads to amphiphilic compounds which can produce polymorphs depending on concentration and $\mathrm{pH}$. Sequences based on L-phenylalanine $(\mathrm{F})$, L-arginine $(\mathrm{R})$, and L-proline $(\mathrm{P})$ combine $\pi$-stacking interactions for the aromatic ring in the phenylalanine side chain, ${ }^{18,19}$ electrostatic interactions of the positively charged arginine side chain, ${ }^{20}$ and hydrophobic properties of the compact proline residue, which is a motif widely used in organocatalysis. ${ }^{21}$ Our group has observed that the concentration of these arginine/phenylalanine-based oligopeptides can influence the shape and morphology of the particles formed. ${ }^{17}$ Also, we saw that the polymorphism is fundamental for understanding the packing of these compounds, in which the presence of proline promotes more rigid and compact systems. ${ }^{22}$

Considering the amyloid oligopeptides $[\mathrm{RF}]_{4}$ and $\mathrm{P}[\mathrm{RF}]_{4}$, in our previous work, ${ }^{22}$ we found the same critical aggregation concentration (cac) in aqueous media, at $25{ }^{\circ} \mathrm{C}$, for both systems $\left(\mathrm{cac}=0.35 \mathrm{mmol} \cdot \mathrm{L}^{-1}\right)$ by steady-state fluorescence spectroscopy, indicating that addition of the hydrophobic proline residue does not affect the aggregation propensity. By electron microscopy and small-angle scattering, we observed that, depending on the peptide concentrations, spherical or elongated aggregates are formed, which have radius dimen-

Received: January 22, 2020

Revised: $\quad$ March 4, 2020

Published: March 4, 2020 
sions of 9.5 and $7.5 \mathrm{~nm}$ for $[\mathrm{RF}]_{4}$ and $\mathrm{P}[\mathrm{RF}]_{4}$, respectively. These peptides were tested as catalysts in aldol reactions involving $p$-nitrobenzaldehyde and cyclohexanone. Contrary to expectation, better conversion and stereoselectivity were observed for the systems containing $[\mathrm{RF}]_{4}$. This effect was attributed to the higher packing factor of $\mathrm{P}[\mathrm{RF}]_{4}$ self-assembly, which hindered reagent attack on the substrate surface, enhancing the enamine transition state.

To examine what happens in these systems if we mix both arginine/phenylalanine peptides mainly in terms of the aldol reaction efficiency, here we investigated the self-assembly and aggregation state for mixtures of the amphiphilic amyloid peptides $[\mathrm{RF}]_{4}$ and $\mathrm{P}[\mathrm{RF}]_{4}$, using spectroscopy, microscopy, and scattering techniques. The combination of these amphiphilic oligopeptides has great potential to produce novel biomaterials and enhance understanding of their selfassembly and polymorphism. It may be possible to create systems with different functional and structural properties when compared to separate peptides. ${ }^{23}$

\section{EXPERIMENTAL METHODS}

Synthesis of Amyloid Peptides. $[\mathrm{RF}]_{4}$ and $\mathrm{P}[\mathrm{RF}]_{4}$ sequences were synthesized using a solid-phase Fmoc strategy. ${ }^{24}$ All chemicals were of analytical or HPLC grades. The protected amino acids, (Fmoc-F-OH), (Fmoc-R(Pbf)-OH), and (Fmoc-P-OH), 1,3-diisopropylcarbodiimide/ $\mathrm{N}$-hydroxybenzotriazole (DIC/HOBt), trifluoroacetic acid (TFA), anisole, thioanisole, dichloromethane (DCM), dimethylformamide (DMF), 1-methyl-2-pyrrolidinone (NMP), and 1,2-ethanedithiol (EDT) were purchased from Sigma-Aldrich (St. Louis, MO). Wang resin with 100-200 mesh size was purchased from Advanced Chemtech (Louisville, KY), with a substitution degree of $0.55 \mathrm{mmol} \cdot \mathrm{g}^{-1}$ and with the first amino acid coupled to the polymeric support. The protecting group was removed by reaction with $20 \%$ of 4-methylpiperidine in dimethylformamide for $30 \mathrm{~min}$. Coupling was carried out in 5.0 fold excess of DIC/HOBt in DCM/DMF $(1: 1, v: v)$. The reactions were monitored using the Kaiser ninhydrin test. ${ }^{25}$ The dry-protected resin was exposed to $90 \%$ trifluoroacetic acid, $5.0 \%$ thioanisole, 3.0\% 1,2-ethanedithiol, and 2.0\% anisole to remove all the protecting groups. After this, the material was lyophilized and analyzed on a liquid-chromatography electrospray ionization mass spectrometer, LC-ESI-MS, yielding $[\mathrm{RF}]_{4}(\mathrm{MM}+\mathrm{H})=1232.6$ (calculated $=1231.6)$ and $\mathrm{P}[\mathrm{RF}]_{4}(\mathrm{MM}+\mathrm{H})=1328.7$ (calculated $=$ 1327.7). ${ }^{22}$ The molecular structures are showed in Figure 1.

Mixing Solutions Containing the Peptides $\mathrm{P}[\mathrm{RF}]_{4}$ and $[\mathrm{RF}]_{4}$. Solutions containing $0.5 \mathrm{wt} \%$ of each peptide were prepared and from these solutions, five systems, with different proportions of $\mathrm{P}[\mathrm{RF}]_{4}$ : $[\mathrm{RF}]_{4}(v / v)$ were made at native $\mathrm{pH} \sim 4$, i.e. 0:1 (1), 3:7 (2); 5:5 (3), 7:3 (4), and 1:0 (5). All solutions were prepared with purified water from a Thermo Scientific Barnstead NANOpure system, with a resistivity of $18.2 \mathrm{~m} \Omega \cdot \mathrm{cm}^{-1}$ (at room temperature) and TOC below $10 \mathrm{ppb}$.

$\mathrm{P}[\mathrm{RF}]_{4}$ and $[\mathrm{RF}]_{4}$ Hydrogels. Hydrogels of systems 1,3 , and 5 were prepared using $3 \mathrm{wt} \%$ of each peptide. The gelation of 3 was observed after $10 \mathrm{~min}$, while heating $\left(60^{\circ} \mathrm{C}, 5 \mathrm{~min}\right)$ followed by cooling $\left(-8{ }^{\circ} \mathrm{C}, 5 \mathrm{~min}\right)$ was performed for 1 and 5 .

Spectroscopy Methods. Fourier transform infrared (FTIR) assays were recorded in the amide band regions using a PerkinElmer Spectrum 100 FTIR spectrometer. Aliquots $(100 \mu \mathrm{L})$ of the sample $\left(0.5\right.$ wt $\%$ peptide solution in $\left.\mathrm{D}_{2} \mathrm{O}\right)$ were sandwiched between two $\mathrm{CaF}_{2}$ plate windows using a plastic spacer of $0.006 \mathrm{~mm}$. The spectra were scanned 16 times in absorbance mode over the range 1800$1300 \mathrm{~cm}^{-1}$, with $4 \mathrm{~cm}^{-1}$ resolution and $1 \mathrm{~cm}^{-1}$ data interval. $\mathrm{A} \mathrm{D}_{2} \mathrm{O}$ spectrum was used as background and subtracted from the samples' experimental data.

Circular dichroism (CD) measurements were performed using a Chirascan spectropolarimeter (Applied Photophysics, UK). Solutions containing $0.5 \mathrm{wt} \%$ of peptide were scanned at $25{ }^{\circ} \mathrm{C}$ in a quartz
$[\mathrm{RF}]_{4}$<smiles>N=C(N)NCCC[C@H](N)C(=O)N[C@@H](Cc1ccccc1)C(=O)N[C@@H](CCCNC(=N)N)C(=O)N[C@@H](Cc1ccccc1)C(=O)N[C@@H](CCCNC(=N)N)C(=O)N[C@@H](Cc1ccccc1)C(=O)N[C@@H](CCCNC(=N)N)C(=O)N[C@@H](Cc1ccccc1)C(=O)O</smiles>

$\mathbf{P}[\mathbf{R F}]_{4}$

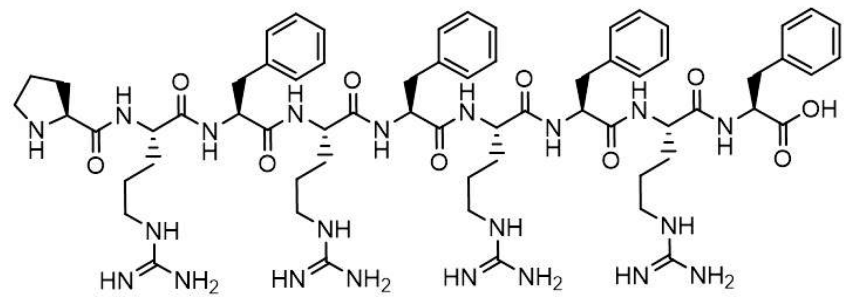

Figure 1. $[\mathrm{RF}]_{4}$ and $\mathrm{P}[\mathrm{RF}]_{4}$ molecular structures.

cuvette with a thickness of $0.01 \mathrm{~mm}$. The spectra were recorded with absorbance $A<2$ at any measured point, considering $0.5 \mathrm{~nm}$ step, 1 $\mathrm{nm}$ bandwidth, and $1 \mathrm{~s}$ collection time per step. A water background $\mathrm{CD}$ signal was used to subtract the baseline from the experimental data.

TEM Imaging. Transmission electron microscopy (TEM) was performed on a JEOL 2100Plus instrument operating at $200 \mathrm{kV}$. Copper grids (Agar Scientific, UK) $5.0 \mathrm{~mm}$ in diameter and $10 \mu \mathrm{m}$ thick, coated with carbon film, were used. The samples were stained with 1 wt \% uranyl acetate (Sigma-Aldrich, UK) and left to dry at room temperature.

Small-Angle X-ray Scattering and X-ray Diffraction. Smallangle X-ray scattering (SAXS) was performed on beamline B21, Diamond Light Source, Didcot, UK. An EMBL BioSAXS robot containing a 96-well plate was used, where $100 \mu \mathrm{L}$ of the 0.5 wt \% peptide solutions was injected via an automated sample exchanger into a quartz capillary, with $1.8 \mathrm{~mm}$ internal diameter, in a vacuum chamber. For the hydrogels, $50 \mu \mathrm{L}$ of each sample was placed in a custom-designed holder and covered with Kapton. The SAXS beamline was operated with a fixed camera length of $3.9 \mathrm{~m}$ and Xray energy of $12.4 \mathrm{keV}$, respectively, and the SAXS pattern was recorded using a PILATUS $2 \mathrm{M}$ detector, with $28 \mathrm{~s}$ per frame. Data processing was performed using ScÅtter, and fitting was performed using SASfit. ${ }^{26}$

Fiber diffraction patterns were recorded using an Oxford Diffraction Gemini Ultra diffractometer with $\mathrm{Cu} \mathrm{K} \alpha$ radiation. For this, oriented stalks were made by suspending droplets of a 5 wt \% peptide solution between the ends of two wax-coated capillaries, letting them dry at room temperature. The data were collected by mounting the stalks vertically in the $\mathrm{X}$-ray diffractometer and collecting diffraction patterns with a Rigaku HyPix-6000HE Hybrid Photon Counting detector, with a sample-to-detector distance of 140 $\mathrm{mm}$, varying the beam angles.

Aldol Reactions. The catalytic efficiency of the peptide mixtures was monitored by the direct aldol reaction using cyclohexanone and $p$-nitrobenzaldehyde. The reactions were performed using different catalyst amounts of 5,10 , and $20 \mathrm{~mol} \%$. Considering the $5 \mathrm{~mol} \%$ catalyst solutions, $20.2 \mu \mathrm{L}$ of cyclohexanone $(0.19 \mathrm{mmol}), 1.0 \mathrm{mg}$ of catalyst $(0.81 \mu \mathrm{mol}), 2.45 \mathrm{mg}$ of $p$-nitrobenzaldehyde $(1.6 \mu \mathrm{mol})$, and $40.4 \mu \mathrm{L}$ of water were used. The solutions were stirred at room temperature for 3 days, and the mixtures were extracted with ethyl 
acetate four times via centrifugation at $4000 \mathrm{rpm}$ for $5 \mathrm{~min}$. The organic phase was then removed on a rotary evaporator, and the samples were solubilized using deuterated chloroform. NMR measurements using a $\left({ }^{1} \mathrm{H}\right)$ Bruker Ultrashield Plus 400 instrument were performed at $400 \mathrm{MHz}$. The yield and diastereomer anti:syn ratio were calculated using the NMR spectra obtained, for which tetramethylsilane (TMS) was used as a reference.

Rheology. Dynamic shear rheometry was performed using a TA Instruments AR-2000 rheometer (TA Instruments). The shear moduli of hydrogels 1,3 , and 5 were measured using a cone-andplate geometry $\left(\right.$ cone radius $=20 \mathrm{~cm}$; cone angle $=1^{\circ}$ ). The linear regime was first determined via stress sweep experiments in the range of $0.1-500 \mathrm{~Pa}$ at a constant angular frequency of $6.28 \mathrm{rad} / \mathrm{s}$ and 20 ${ }^{\circ} \mathrm{C}$. Oscillatory frequency sweep experiments were then performed at constant stress within the linear regime and angular frequencies from 0.1 to $200 \mathrm{rad} / \mathrm{s}$ at $20{ }^{\circ} \mathrm{C}$.

\section{RESULTS}

Characterization of the Mixtures of $[\mathrm{RF}]_{4}$ and $\mathrm{P}[\mathrm{RF}]_{4}$. Following our previous study comparing $[\mathrm{RF}]_{4}$ and $\mathrm{P}[\mathrm{RF}]_{4}{ }^{22}$ we monitored the self-assembly of the mixtures of these peptides in aqueous solution. Considering the critical aggregation concentration (cac) of $\sim 0.35 \mathrm{mmol} \mathrm{L}^{-1}$ for both $[\mathrm{RF}]_{4}$ and $\mathrm{P}[\mathrm{RF}]_{4}$ at $25^{\circ} \mathrm{C}^{22}$ solutions above the cac $(0.5 \mathrm{wt}$ $\%)$ of each peptide were prepared as stock solutions, and then the $v / v$ mixtures of peptides at native $\mathrm{pH}(\sim 6)$ were characterized.

FTIR and CD measurements were performed to analyze changes in the peptide secondary structure. The FTIR spectra are shown in Figure 2a. Four bands were observed for both samples. More details of the peaks are provided in Table S1. All the solutions have a sharp peak at approximately $1672 \mathrm{~cm}^{-1}$ (peak 1), attributed to the vibrations from TFA counterions

a)

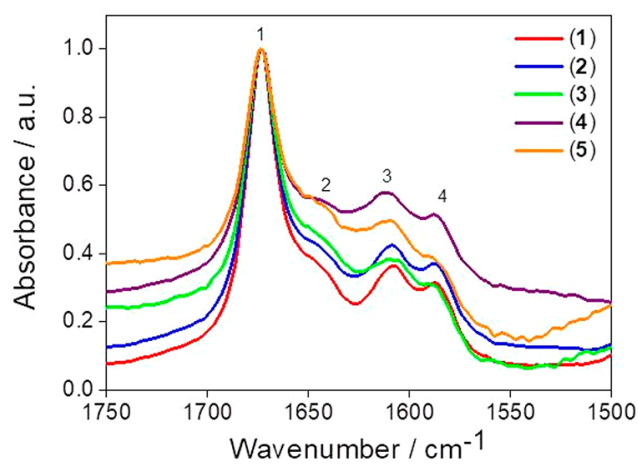

b)

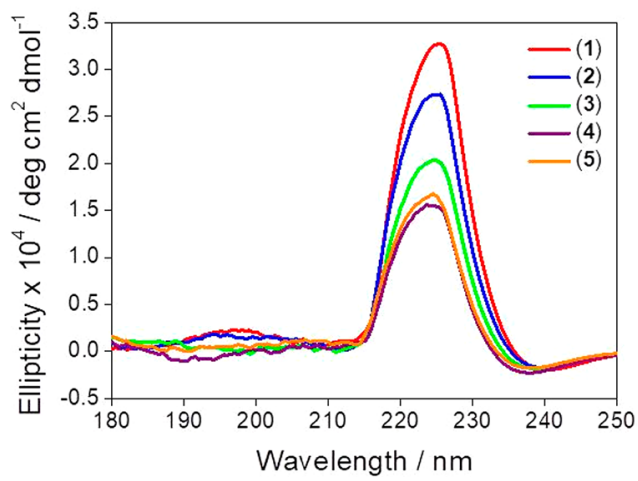

Figure 2. Spectroscopic characterization of $\mathrm{P}[\mathrm{RF}]_{4}:[\mathrm{RF}]_{4}$ mixtures $0: 1(1), 3: 7(2) ; 5: 5(3), 7: 3(4)$, and 1:0 (5), above the cac in water, using (a) FTIR and (b) CD. bound to peptides molecules. ${ }^{27}$ Peak 2 at $1638-1646 \mathrm{~cm}^{-1}$ is less pronounced but is correlated with unordered structures present in the system. ${ }^{22}$ The vibrational bands of the arginine side chain ${ }^{22,28,29}$ lead to peaks 3 and $4\left(1607\right.$ and $1585 \mathrm{~cm}^{-1}$, respectively). Also, peak 3 may be assigned to a contribution from $\beta$-sheet. ${ }^{17}$

CD spectra presented in Figure $2 \mathrm{~b}$ show two positive bands, one located at $\sim 195 \mathrm{~nm}$, correlated with antiparallel $\beta$-sheet conformation, $^{22}$ and the other at $219 \mathrm{~nm}$, characteristic of phenylalanine $n-\pi^{*}$ electronic transitions. ${ }^{30,31}$ Looking at the $\mathrm{CD}$ absorption spectra in this region (Figure S1), a hypsochromic effect and an enhancement of the absorption band intensity can be observed as the amount of prolinepeptide increases in the mixtures. This effect can be correlated to a more hydrophobic environment with a higher $\mathrm{P}[\mathrm{RF}]_{4}$ content, due to the presence of the imino groups present in the proline side chain. The decrease in the intensity of the CD bands was attributed to the interacting ordered $\pi$-conjugated systems, a common feature of the $\beta$-sheet structure, with a contribution also from a $\beta$-turn-like conformation. Consequently, a slight enhancement of the CD peak width was observed for the systems containing more of the prolinecontaining peptide, as can be seen in Figure $2 b$.

Fiber X-ray diffraction was performed to obtain structural information and the influence of proline on the secondary structure. The fiber XRD patterns were reduced to onedimensional intensity profiles, which show six peaks (Figure 3 ). Table 1 summarizes the associated $d$-spacings.

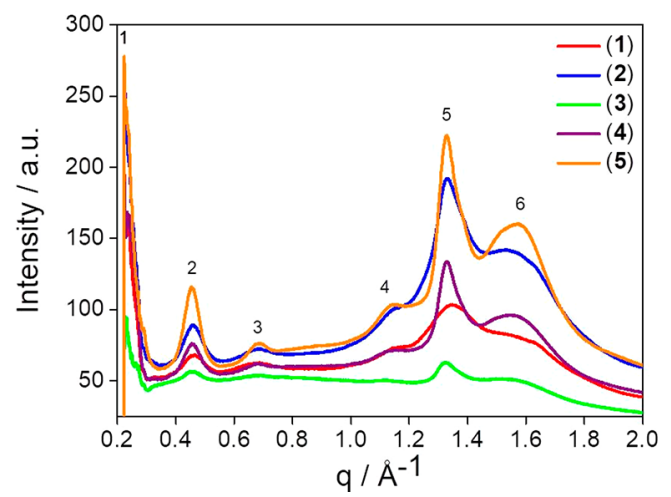

Figure 3. $\mathrm{XRD}$ results obtained of $\mathrm{P}[\mathrm{RF}]_{4}:[\mathrm{RF}]_{4}$ mixtures $0: 1$ (1), 3:7 (2); 5:5 (3), 7:3 (4), and 1:0 (5), at native $\mathrm{pH}$.

The spacing $d \sim 4.7 \AA$ (peak 5) can be associated with the separation between adjacent peptide backbones organized into $\beta$-strands, ${ }^{32}$ and the $d \sim 9.4 \AA$ peak corresponds to the antiparallel organization of the chains, which is characterized

Table 1. Summary of theXRD Results of $P[R F]_{4}:[R F]_{4}$ Mixtures 0:1 (1), 3:7 (2); 5:5 (3), 7:3 (4), and 1:0 (5), at Native $\mathrm{pH}$

\begin{tabular}{ccccccc} 
& \multicolumn{7}{c}{$d(\AA) \pm 0.1 \AA$} \\
\cline { 2 - 7 } sample & $\mathbf{1}$ & $\mathbf{2}$ & $\mathbf{3}$ & $\mathbf{4}$ & $\mathbf{5}$ & $\mathbf{6}$ \\
$\mathbf{1}$ & 28.6 & 13.7 & 9.2 & 5.5 & 4.6 & 3.8 \\
$\mathbf{2}$ & 28.6 & 13.7 & 9.2 & 5.6 & 4.7 & 4.0 \\
$\mathbf{3}$ & 27.3 & 13.7 & 9.2 & 5.7 & 4.7 & 4.0 \\
$\mathbf{4}$ & 28.6 & 13.9 & 9.2 & 5.5 & 4.7 & 4.0 \\
$\mathbf{5}$ & 28.6 & 13.7 & 9.1 & 5.5 & 4.7 & 4.0
\end{tabular}


by twice the $\beta$-strand separation. ${ }^{33,34}$ The peaks at approximately $28.6 \AA$ (1), $13.7 \AA$ (2), and $9.2 \AA$ (3) suggest the presence of lamellar ordering. ${ }^{20,35}$ The peaks $5.5 \AA$ (4) and 4.0 $\AA$ (6) correspond to a fraction of peptide in unordered conformation. $^{36}$ Thus, the peaks can be indexed to an orthorhombic unit cell, with $a=28.6 \AA$, $b \sim 9.2 \AA$, and $c \sim$ $9.2 \AA^{35}$ The spacings in Table 1 are the same for all systems within estimated uncertainties. A representative illustration of the packing of the peptide chain in the unit cell is shown in Figure 4.

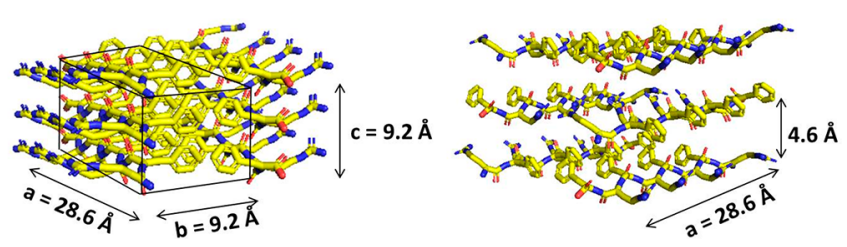

Figure 4. Schematic representation of the orthorhombic unit cell, considering the dimensions obtained by fiber XRD for $[R F]_{4}$.

TEM was used to image self-assembled structures above cac (at native $\mathrm{pH}$ ). This revealed the presence of long fibers with lengths on the micrometer scale. Figure $5 \mathrm{a}-\mathrm{e}$ shows the
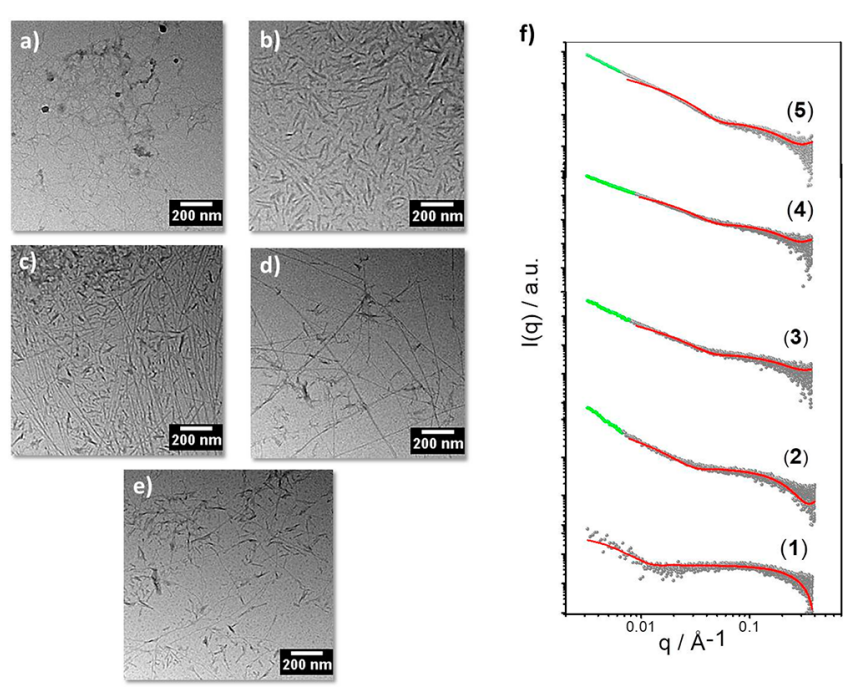

Figure 5. TEM images of $0.5 \mathrm{wt} \%$ peptide aqueous solutions. (a) $\mathbf{1}$, (b) 2, (c) 3, (d) 4, and (e) 5, at native pH. (f) SAXS data (gray points) of peptide solutions above the cac and at native $\mathrm{pH}$. Model fits (red line) using the model described in the text and fitting excluding data (green line), characteristic of the structure factor. influence on the orientation and size of the structures with changes in the composition of the mixtures. The system containing $[\mathrm{RF}]_{4}(\mathbf{1})$ was characterized by thin fibers, with diameters $<10 \mathrm{~nm}$, and the coexistence of globular fractal aggregates. Adding $\mathrm{P}[\mathrm{RF}]_{4}$, a predominance of fibers with approximately $10 \mathrm{~nm}$ diameter was observed. For the mixtures, the TEM images reveal for 2 the presence of short fibers, for 3 the coexistence of short and long fibers, and for 4 the appearance of long fibers, similar to the system containing only $\mathrm{P}[\mathrm{RF}]_{4}(\mathbf{5})$.

SAXS measurements were performed to obtain more detail about the nanoscale shape and dimensions in the mixtures. A first analysis of the curves, considering the intensity decay in the Guinier regime, provides information about the form factor, as can be seen in Figure S2. Peptide $P[R F]_{4}$ and the mixtures show $I \sim q^{-n}$ with $n=1.7$ and 1.6 to 1.8 , respectively, which suggest a surface mass fractal form factor, ${ }^{26}$ while the $[\mathrm{RF}]_{4}$ samples have $n=2.5$, characteristic of a volumetric mass fractal. ${ }^{26}$ Structure factor effects at low $q$ were excluded (as indicated by the green line regions in Figure 5f). ${ }^{37}$

The SAXS data were fitted using the software SASFit. ${ }^{26}$ The red curves in Figure $2 \mathrm{f}$ represent adjusted form factors. System 1 was modeled by applying a mass fractal form factor. The spectroscopy and microscopy results discussed above indicate that the other systems $(\mathbf{2}-\mathbf{5})$ are characterized by an extended $\beta$-sheet structure range. Consequently, a long cylindrical shell model (with fixed cylinder length, $1000 \mathrm{~nm}$ ) was used as a second form factor, just adjusting the weighting of the two contributions. Also, for both form factor models, a Gaussian size distribution $\left(\sigma_{\mathrm{R}}\right)$ of the radius was included. Table 2 summarizes the fitted parameters.

The parameters in Table 2 indicate a gradual increase of the fractal cluster radius ( $\left.\mathrm{R}^{\prime}\right)$ with increasing $\mathrm{P}[\mathrm{RF}]_{4}$ content in the systems, from $0.65 \mathrm{~nm}$ for sample 1 to $1.0 \mathrm{~nm}$ for 5 . However, a decrease of fractal dimension (D) was observed as the $\mathrm{P}[\mathrm{RF}]_{4}$ content increases, suggesting the presence of more compact clusters. Table 2 also shows a decrease in the cylinder radius $(R)$ and the shell thickness of the cylinders $(\Delta R)$ with increasing $\mathrm{P}[\mathrm{RF}]_{4}$ content. This effect suggests that the proline helps molecular packing, leading to more compact structures. The model fitting also reveals variations in the (electron) scattering length density of the core $\left(\eta_{\text {core }}\right)$ and the shell $\left(\eta_{\text {shell }}\right)$. A considerable increase of $\eta_{\text {core }}$ was observed in the samples with more $\mathrm{P}[\mathrm{RF}]_{4}$, which also has a lower radius. These results confirm the higher packing of the peptide molecules in the core of the fibers.

On the basis of the observed fiber XRD modeling (Figure 3) and the observed fibril structures from cryo-TEM and SAXS, we propose that the $\beta$-sheets are arranged in a typical amyloid fashion with the sheets parallel to the fiber axis and the $\beta$ -

Table 2. Summary of the Model Parameters Obtained from the Fitting Procedure of SAXS Data ${ }^{a}$

\begin{tabular}{|c|c|c|c|c|c|c|c|c|c|c|c|c|}
\hline \multirow[b]{2}{*}{ sample } & \multicolumn{4}{|c|}{ mass fractal Gaussian } & \multicolumn{6}{|c|}{ long cylindrical shell } & \multicolumn{2}{|c|}{ fit quality } \\
\hline & $N_{1}$ & $R^{\prime}(\mathrm{nm})$ & $\sigma_{\mathrm{R}}(\mathrm{nm})$ & $D(\mathrm{~nm})$ & $\mathrm{N}_{2}$ & $R(\mathrm{~nm})$ & $\sigma_{\mathrm{R}}(\mathrm{nm})$ & $\Delta R(\mathrm{~nm})$ & $\eta_{\text {core }}$ & $\eta_{\text {shell }}$ & $R_{\mathrm{v}}$ & $\chi^{2}$ \\
\hline 1 & 0.95 & 0.65 & 0.002 & 2.0 & 0.05 & 21.4 & 0.33 & 1.55 & $4.6 \times 10^{-9}$ & $2.2 \times 10^{-9}$ & 0.19 & 0.17 \\
\hline 2 & 0.30 & 0.91 & 0.04 & 2.6 & 0.70 & 9.4 & 1.85 & 0.42 & $8.0 \times 10^{-9}$ & $4.0 \times 10^{-8}$ & 0.16 & 0.18 \\
\hline 3 & 0.10 & 0.98 & 0.05 & 2.2 & 0.90 & 4.2 & 0.90 & 0.75 & $3.4 \times 10^{-8}$ & $1.8 \times 10^{-7}$ & 0.22 & 0.57 \\
\hline 4 & 0.20 & 1.03 & 0.005 & 1.6 & 0.80 & 3.0 & 1.00 & 0.90 & $6.5 \times 10^{-8}$ & $2.5 \times 10^{-7}$ & 0.27 & 1.81 \\
\hline 5 & 0.10 & 1.03 & 0.005 & 1.5 & 0.90 & 2.8 & 1.00 & 0.91 & $7.0 \times 10^{-8}$ & $2.7 \times 10^{-7}$ & 0.29 & 2.62 \\
\hline
\end{tabular}

${ }^{a}$ The scattering length density of the solvent $\left(\eta_{\text {solv }}\right)$ was fixed at $9.7 \times 10^{-9} . N_{1}$ and $N_{2}$ represent the fractional contribution of the two form factor components to the total intensity. Fit quality is assessed via the $R$-factor $\left(R_{\mathrm{v}}\right)$ and the reduced chi square $\left(\chi^{2}\right)$ value. 
strands perpendicular to it. The dispersity in the cylinder radius points to differences in the number of $\beta$-sheet stacks.

In our previous work, we found that these peptides can be used as organocatalysts in direct aldol reactions, involving cyclohexanone and p-nitrobenzaldehyde in water. In this case, a dependence on the reaction efficiency on peptide packing was observed. ${ }^{22}$ We saw lower conversion and stereoselectivity for $\mathrm{P}[\mathrm{RF}]_{4}$ systems due to the formation of more elongated structures, in which the neighboring aromatic rings may be tightly packed, hindering the reactant's interactions with the active sites. $^{38-42}$ Here, the efficiency of the $\mathrm{P}[\mathrm{RF}]_{4}:[\mathrm{RF}]_{4}$ mixtures as catalysts was monitored considering the direct aldol reactions using cyclohexanone and $p$-nitrobenzaldehyde, examining whether it is possible to enhance the conversion in the combinations.

The reactions were performed at room temperature for 3 days, varying the catalyst amount ( $5 \mathrm{~mol} \%$ and $20 \mathrm{~mol} \%$ ) in aqueous media and at native $\mathrm{pH}$. The results are summarized in Table 3. The NMR results can be seen in Figure S3, and the

Table 3. Comparative Results of the Aldol Reactions between $p$-Nitrobenzaldehyde and Cyclohexanone Catalyzed by the Peptide Mixtures in the Water at Native $\mathrm{pH}^{a}$

$\begin{array}{lcccccc}\text { entry }^{b} & \text { sample } & \begin{array}{c}\text { catalyst } \\ (\mathrm{mol} \%)\end{array} & \begin{array}{c}\mathrm{H}_{2} \mathrm{O}^{c} \\ (\text { equiv })\end{array} & \begin{array}{c}\text { conv }^{d} \\ (\%)\end{array} & \text { anti:syn } & \begin{array}{c}\text { ee } \\ (\%)\end{array} \\ 1(\mathrm{~s}) & \mathbf{1} & 5 & 2 & 36.9 & 69: 31 & 58 \\ 2(\mathrm{~s}) & \mathbf{2} & 5 & 2 & 28.7 & 70: 30 & 51 \\ 3(\mathrm{~s}) & 3 & 5 & 2 & 18.1 & 71: 29 & 58 \\ 4(\mathrm{~s}) & \mathbf{4} & 5 & 2 & 7.0 & 64: 36 & 38 \\ 5(\mathrm{~s}) & \mathbf{5} & 5 & 2 & 12.7 & 70: 30 & 6.1 \\ 6(\mathrm{~g}) & \mathbf{1} & 20 & 2 & 57.4 & 57: 43 & 50 \\ 7(\mathrm{~g}) & \mathbf{2} & 20 & 2 & 42.4 & 70: 30 & 37 \\ 8(\mathrm{~g}) & \mathbf{3} & 20 & 2 & 45.0 & 72: 28 & 43 \\ 9(\mathrm{~g}) & \mathbf{4} & 20 & 2 & 43.9 & 76: 24 & 13 \\ 10(\mathrm{~g}) & \mathbf{5} & 20 & 2 & 53.9 & 60: 40 & 18\end{array}$

${ }^{a}$ The reactions were promoted at room temperature under vigorous stirring for 3 days, using 12 equiv of cyclohexanone, 1 equiv of $p$ nitrobenzaldehyde, $5-20 \mathrm{~mol} \%$ of catalyst, $2 \times$ volume of cyclohexanone for water. ${ }^{b}(\mathrm{~s})$ indicates molecules in solution; $(\mathrm{g})$ indicates supramolecular gels. ${ }^{c}$ Excess water relative to cyclohexanone $(v / v) .{ }^{d}$ Conversion and diastereoselectivity were determined by ${ }^{1} \mathrm{H}$ NMR analysis of the crude product. ${ }^{e}$ Diastereomeric anti:syn ratios were determined by ${ }^{1} \mathrm{H}$ NMR analysis of the crude product.

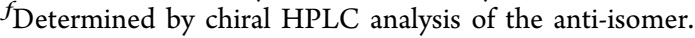

HPLC results for the racemic aldol product are shown in Figure S4. For the lowest catalyst concentration, homogeneous solutions were observed, while with the increase of catalyst concentration to $20 \mathrm{~mol} \%$, supramolecular gels were formed during the reaction. Considering the results presented in Table 3 , the best response is represented by entry 1 , which used 5 mol \% of $[\mathrm{RF}]_{4}$ peptides which led to moderate conversion (36.9\%) and a good stereoselectivity (69:31), with 58\% enantiomeric excess (ee). As the amount of $\mathrm{P}[\mathrm{RF}]_{4}$ increases, a considerable decrease of the conversion was observed, especially for entry 4 compared to the other $5 \mathrm{~mol} \%$ catalyzed reactions. Entry 5, containing only $\mathrm{P}[\mathrm{RF}]_{4}$ as catalyst, presented a low conversion, but better than the system characterized by entry $4\left(70 \% \mathrm{P}[\mathrm{RF}]_{4}\right.$ and $\left.30 \%[\mathrm{RF}]_{4}\right)$, and the lowest ee. This effect can be correlated with the packing factor, because more compact systems can hinder the attack of the reagents onto the catalytic surface, increasing the energetic barrier to the enamine transition state formation and consequently decreasing the efficiency of the aldol reactions. As observed, for example by Diaz and co-workers, ${ }^{43}$ the absence of the catalyst prevents conversion for the monitored aldol reaction. Pioneering studies by Hajos and Parrish ${ }^{44}$ and by Eder, Sauer, and Wiechert ${ }^{45}$ described the first organocatalyzed intramolecular aldol reaction by L-proline, resulting in high yield and excellent enantioselectivity, ${ }^{45,46}$ proving the importance of a proline-based catalyst. The reactions mediated by proline feature high enantioselectivity, due to its ability to promote the formation of highly organized transition states, and its high nucleophilic reactivity with carbonyl compounds compared with primary amino acids. ${ }^{47,48}$

The same effect was observed considering the $20 \mathrm{~mol} \%$ catalyst reactions, but in this case, the difference between the reaction conversions and enantiomeric excess was lower, except for Entry 10, which presents an increase of three times the e.e. in comparison with the Entry 5. Also, the peptide mixtures showed similar conversion and high diastereoselectivity; Entry 9 corresponds to the best conditions with good conversion (43.9\%) and stereoselectivity (76:24).

Due to the presence of self-assembled extended fibrils, we reasoned that at high concentrations, hydrogelation might be observed. $^{49,50}$ Even without $\mathrm{pH}$ adjustment, hydrogel formation was observed at 3 wt \% of each peptide, soft gels being obtained, as can be seen in Figure 6a. To get information about

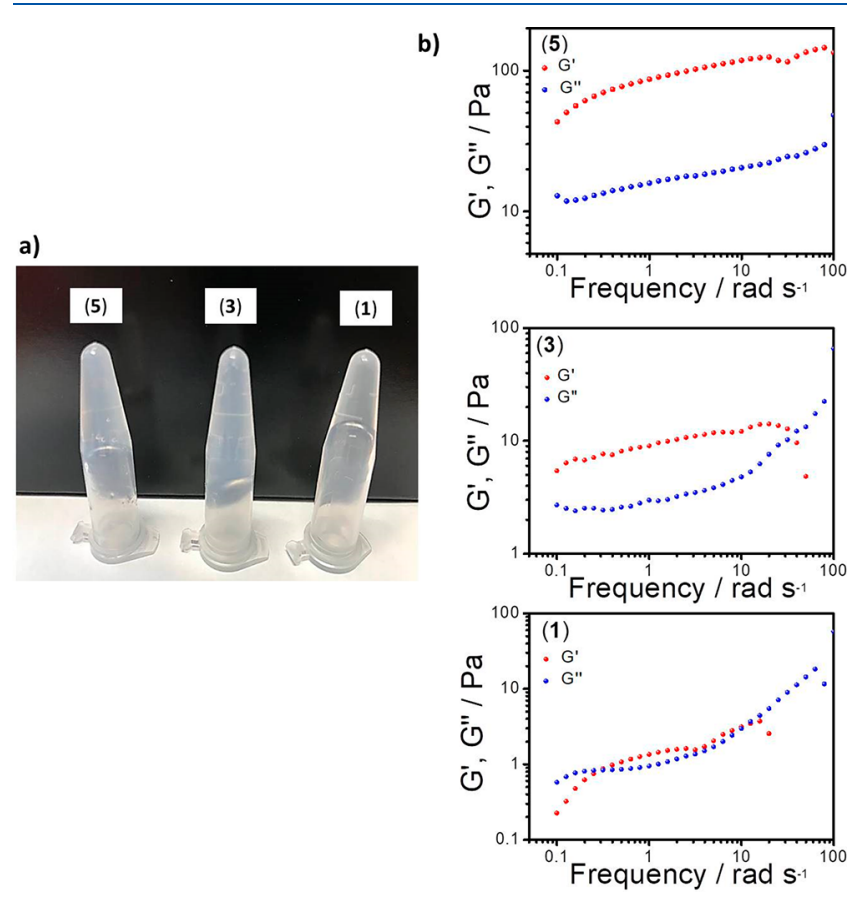

Figure 6. (a) Images of the hydrogels formed by $3 \mathrm{wt} \%$ peptide samples, as indicated. (b) Storage and shear modulus obtained by rheology experiments in frequency sweep mode, using $\sigma=3 \mathrm{~Pa}$ for $\mathbf{1}$, $1 \mathrm{~Pa}$ for 3 , and $5 \mathrm{~Pa}$ for 5 .

the viscoelastic properties of these materials, rheology experiments were performed. Initially, the stress $(\sigma)$ was varied at a constant frequency $\left(\omega=6.28 \mathrm{rad} \mathrm{s}^{-1}\right)$ to determine the linear viscoelastic regime. Then frequency sweeps were performed at a stress value in the linear regime. Figure S5 shows the linear regime extends up to $\sigma=5$ to $10 \mathrm{~Pa}$, depending on the mixture composition. 
Frequency sweep measurements were then performed. Figure $6 \mathrm{~b}$ shows a low-frequency Newtonian plateau in the moduli with $G^{\prime}>G^{\prime \prime}$, for the systems 3 and $\mathbf{5}$, consistent with a well-defined gel-like response. ${ }^{51-53}$ For $1, G^{\prime}$ and $G^{\prime \prime}$ are similar in magnitude and have plateau values of $G^{\prime}<1 \mathrm{~Pa}$, which is characteristic of a soft gel. ${ }^{54}$

SAXS was used to characterize the structure within the gels. The SAXS fitting curves of the 3 wt \% hydrogels, shown in Figure $7 \mathrm{a}$, were obtained using a long cylindrical shell form a)

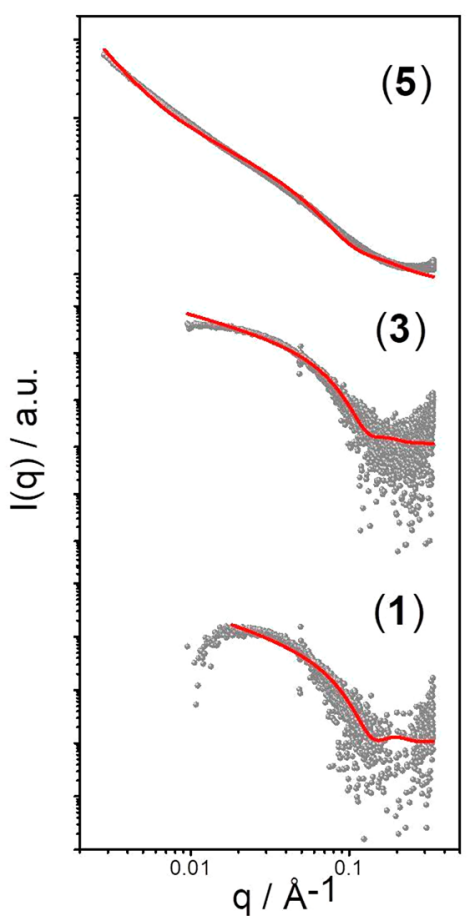

b)

(5)

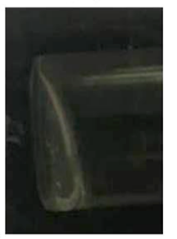

(3)

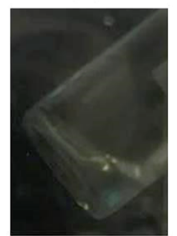

(1)

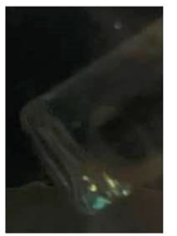

Figure 7. (a) SAXS data (gray) and fitted curves (red) using a long cylinder shell form factor model, for 3 wt \% hydrogels of 1, 3, and $\mathbf{5 .}$ (b) Images of the birefringence between crossed polarizers for $3 \mathrm{wt} \%$ hydrogels of 1,3 , and 5 .

factor. Systems 1 and 3 presented less information at the low $q$ region, indicating more unordered structures. The fitted parameters are shown in Table S2, and they show a gradual decrease in fibril radius increasing the $\mathrm{P}[\mathrm{RF}]_{4}$ content, from $2.5 \mathrm{~nm}$ for sample 1 to $0.7 \mathrm{~nm}$ for 5 . The fibril core radius and shell thickness values are lower than for the corresponding SAXS patterns for solutions (Table 2) showing that the hydrogels contain finer stranded fibril network structures. A similar shell thickness of the cylinders was observed for all systems, and considering scattering length density, samples 1 and 3 show higher core electron density. However, the scattering density value difference between the core and the shell for the system $\mathbf{1}$ is more significant than for 3 . The opposite was found for the system $\mathbf{5}$, which shows a concentration of electron density in the shell.

Remarkably, the hydrogels were found to show birefringence, placing the 3 wt \% hydrogels, contained in glass flasks, between crossed polarizers (Figure $7 \mathrm{~b}$ ). An increase of the anisotropy is seen for the sample containing only $[\mathrm{RF}]_{4}$, as can be seen in Figure 7.

\section{CONCLUSIONS}

We have investigated the self-assembled morphology of the $[\mathrm{RF}]_{4}: \mathrm{P}[\mathrm{RF}]_{4}$ mixtures, SAXS showing that the peptides selfassemble to form small fractal clusters coexisting with extended elongated fibers. The fibers comprise peptides with a $\beta$-sheet conformation, and the peptide chains pack in an orthorhombic unit cell. By studying model stereoselective aldol reactions, we showed that the concentration of the catalyst used can influence the conversion and stereoselectivity of the aldol reactions due to the polymorphism and availability of the reagents on the catalyst surface. We demonstrated that the $[\mathrm{RF}]_{4}$ peptide, which lacks a proline residue, unexpectedly has a higher catalytic efficiency than $\mathrm{P}[\mathrm{RF}]_{4}$. Also, stable and soft hydrogels were observed, characterized by long cylinder structures. However, in comparison with the liquid systems, the fibrils in the hydrogels are significantly smaller in radius, especially with increasing $\mathrm{P}[\mathrm{RF}]_{4}$ content. Another significant change was correlated with the electron density distribution in the fibrils, with a concentration in the shell instead of the core, as was observed for the solutions. The hydrogels are birefringent, which along with SAXS data showing fibril form factor features, indicates that they possess the character of nematic hydrogels. Nematic hydrogels have rarely been reported for peptide systems. Our study provides a wealth of information on the polymorphism that can be accessed by tuning mixture composition in these model peptide systems. As the systems containing more $\mathrm{P}[\mathrm{RF}]_{4}$ were characterized by tight molecular packing, they do not have good aldol reaction efficiency, due to the difficulty of access of the reagents to the catalytic site of formation of the enamine transition state. Our findings show that hydrogel stiffness can also be increased by the addition of $\mathrm{P}[\mathrm{RF}]_{4}$ in comparison to those formed by $[\mathrm{RF}]_{4}$ alone. Our results indicate the scope that is available to control peptide self-assembly, catalytic activity, and hydrogel formation by mixing closely related peptide homologues.

\section{ASSOCIATED CONTENT}

\section{(s) Supporting Information}

The Supporting Information is available free of charge at https://pubs.acs.org/doi/10.1021/acs.langmuir.0c00198.

Table of FTIR peak positions, UV absorption spectra, additional SAXS data, NMR spectra and HPLC curves for aldol reactions, stress sweep rheology data, SAXS fit parameters for hydrogels (PDF)

\section{AUTHOR INFORMATION}

\section{Corresponding Authors}

Wendel A. Alves - Centro de Ciencias Naturais e Humanas, Universidade Federal do ABC, 09210-580 Santo André, Brazil; 이이.orid.org/0000-0002-8394-2751;

Email: wendel.alves@ufabc.edu.br

Ian W. Hamley - Department of Chemistry, University of Reading, Reading RG6 6AD, United Kingdom; 이이.org/ 0000-0002-4549-0926; Email: I.W.Hamley@reading.ac.uk

\section{Authors}

Juliane N. B. D. Pelin - Centro de Cîncias Naturais e Humanas, Universidade Federal do ABC, 09210-580 Santo Andre, Brazil; Department of Chemistry, University of Reading, Reading RG6 6AD, United Kingdom

Barbara B. Gerbelli - Centro de Cîncias Naturais e Humanas, Universidade Federal do ABC, 09210-580 Santo André, Brazil 
Charlotte J. C. Edwards-Gayle - Department of Chemistry, University of Reading, Reading RG6 6AD, United Kingdom

Andrea M. Aguilar - Instituto de Cîncias Ambientais, Quimicas e Farmacêuticas, Universidade Federal de São Paulo, Diadema 09972-270, Brazil

Valeria Castelletto - Department of Chemistry, University of Reading, Reading RG6 6AD, United Kingdom; 이이.org/ 0000-0002-3705-0162

Complete contact information is available at: https://pubs.acs.org/10.1021/acs.langmuir.0c00198

\section{Notes}

The authors declare no competing financial interest.

\section{ACKNOWLEDGMENTS}

This work was supported by FAPESP (grant no. 2017/023172) and $\mathrm{CNPq}$ (grant no. 304389/2019-6). INCT in Bioanalytics (FAPESP grant no. 2014/50867-3 and CNPq grant no. 465389/2014-7) is kindly acknowledged for the grants. J.N.B.D.P. acknowledges FAPESP (project number 2015/20446-9 and 2018/12535-0) for a doctoral fellowship and the research internship abroad program (BEPE). B.B.G. acknowledges FAPESP (project number 2018/05888-3) for a doctoral and postdoctoral fellowship. We thank Diamond for the award of beamtime on beamline B21 (SM18523-2 and SM21470-1). I.W.H. thanks EPSRC for the award of a Platform Grant (ref EP/L020599/1). The authors are grateful for access to the Chemical Analysis Facility at the University of Reading.

\section{REFERENCES}

(1) Hamley, I. W. Small Bioactive Peptides for Biomaterials Design and Therapeutics. Chem. Rev. 2017, 117, 14015-14041.

(2) Geng, J.; Qu, K.; Ren, J.; Qu, X. Rapid and efficient screening of Alzheimer's disease $\beta$-amyloid inhibitors using label-free gold nanoparticles. Mol. BioSyst. 2010, 6, 2389-2391.

(3) Takahashi, T.; Mihara, H. Peptide and Protein Mimetics Inhibiting Amyloid $\beta$-Peptide Aggregation. Acc. Chem. Res. 2008, 41, 1309-1318.

(4) Wei, G.; Su, Z.; Reynolds, N. P.; Arosio, P.; Hamley, I. W.; Gazit, E.; Mezzenga, R. Self-assembling peptide and protein amyloids: from structure to tailored function in nanotechnology. Chem. Soc. Rev. 2017, 46, 4661-4708.

(5) Hamley, I. W. Lipopeptides: from self-assembly to bioactivity. Chem. Commun. 2015, 51, 8574-8583.

(6) Cui, H.; Webber, M. J.; Stupp, S. I. Self-assembly of peptide amphiphiles: from molecules to nanostructures to biomaterials. Biopolymers 2010, 94, 1-18.

(7) Bianchi, R. C.; da Silva, E. R.; Dall'Antonia, L. H.; Ferreira, F. F.; Alves, W. A. A Nonenzymatic Biosensor Based on Gold Electrodes Modified with Peptide Self-Assemblies for Detecting Ammonia and Urea Oxidation. Langmuir 2014, 30, 11464-11473.

(8) Silva, R. F.; Araújo, D. R.; Silva, E. R.; Ando, R. A.; Alves, W. A. L-Diphenylalanine Microtubes as a Potential Drug-Delivery System: Characterization, Release Kinetics, and Cytotoxicity. Langmuir 2013, 29, 10205-10212.

(9) Silva, E. R.; Cooney, G.; Hamley, I. W.; Alves, W. A.; Lee, S.; O’Connor, B. F.; Reza, M.; Ruokolainen, J.; Walls, D. Structural behaviour and gene delivery in complexes formed between DNA and arginine-containing peptide amphiphiles. Soft Matter 2016, 12, 91589169.

(10) Cui, Y.; Kim, S. N.; Naik, R. R.; McAlpine, M. C. Biomimetic Peptide Nanosensors. Acc. Chem. Res. 2012, 45, 696-704.

(11) Dehsorkhi, A.; Castelletto, V.; Hamley, I. W. Self-assembling amphiphilic peptides. J. Pept. Sci. 2014, 20, 453-467.
(12) Hamley, I. W. Self-assembly of amphiphilic peptides. Soft Matter 2011, 7, 4122-4138.

(13) Brown, S.; Sarikaya, M.; Johnson, E. A genetic analysis of crystal growth. J. Mol. Biol. 2000, 299, 725-735.

(14) Naik, R. R.; Stringer, S. J.; Agarwal, G.; Jones, S. E.; Stone, M. O. Biomimetic synthesis and patterning of silver nanoparticles. Nat. Mater. 2002, 1, 169-172.

(15) Hamley, I. W. The Amyloid Beta Peptide: A Chemist's Perspective. Role in Alzheimer's and Fibrillization. Chem. Rev. 2012, 112, 5147-5192.

(16) Cui, H.; Webber, M. J.; Stupp, S. I. Self-assembly of peptide amphiphiles: From molecules to nanostructures to biomaterials. Biopolymers 2010, 94, 1-18.

(17) Silva, E. R.; Listik, E.; Han, S. W.; Alves, W. A.; Soares, B. M.; Reza, M.; Ruokolainen, J.; Hamley, I. W. Sequence length dependence in arginine/phenylalanine oligopeptides: Implications for selfassembly and cytotoxicity. Biophys. Chem. 2018, 233, 1-12.

(18) Adler-Abramovich, L.; Vaks, L.; Carny, O.; Trudler, D.; Magno, A.; Cafllish, A.; Frenkel, D.; Gazit, E. Phenylalanine assembly into toxic fibrils suggests amyloid etiology in phenylketonuria. Nat. Chem. Biol. 2012, 8, 701-706.

(19) Guo, C.; Luo, Y.; Zhou, R.; Wei, G. Probing the Self-Assembly Mechanism of Diphenylalanine-Based Peptide Nanovesicles and Nanotubes. ACS Nano 2012, 6, 3907-3918.

(20) Liberato, M. S.; Kogikoski, S.; Silva, E. R.; Coutinho-Neto, M. D.; Scott, L. P. B.; Silva, R. H.; Oliveira, V. X.; Ando, R. A.; Alves, W. A. Self-Assembly of Arg-Phe Nanostructures via the Solid-Vapor Phase Method. J. Phys. Chem. B 2013, 117, 733-740.

(21) List, B.; Lerner, R. A.; Barbas, C. F. Proline-Catalyzed Direct Asymmetric Aldol Reactions. J. Am. Chem. Soc. 2000, 122, 23952396.

(22) Pelin, J. N. B. D.; Gerbelli, B. B.; Soares, B. M.; Aguilar, A. M.; Alves, W. A. Amyloidogenic model peptides as catalysts for stereoselective aldol reactions. Catal. Sci. Technol. 2019, 9, 43044313.

(23) Castelletto, V.; Kaur, A.; Hamley, I. W.; Barnes, R. H.; Karatzas, K. A.; Hermida-Merino, D.; Swioklo, S.; Connon, C. J.; Stasiak, J.; Reza, M.; Ruokolainen, J. Hybrid membrane biomaterials from selfassembly in polysaccharide and peptide amphiphile mixtures: controllable structural and mechanical properties and antimicrobial activity. RSC Adv. 2017, 7, 8366-8375.

(24) Carpino, L. A.; Han, G. Y. 9-Fluorenylmethoxycarbonyl function, a new base-sensitive amino-protecting group. J. Am. Chem. Soc. 1970, 92, 5748-5749.

(25) Kaiser, E.; Colescott, R. L.; Bossinger, C. D.; Cook, P. I. Color test for detection of free terminal amino groups in the solid-phase synthesis of peptides. Anal. Biochem. 1970, 34, 595-598.

(26) Bressler, I.; Kohlbrecher, J.; Thünemann, A. F. SASfit: a tool for small-angle scattering data analysis using a library of analytical expressions. J. Appl. Crystallogr. 2015, 48, 1587-1598.

(27) Eker, F.; Griebenow, K.; Schweitzer-Stenner, R. A $\beta 1-28$ Fragment of the Amyloid Peptide Predominantly Adopts a Polyproline II Conformation in an Acidic Solution. Biochemistry 2004, 43, 6893-6898

(28) Ghosh, A.; Tucker, M. J.; Hochstrasser, R. M. Identification of Arginine Residues in Peptides by 2D-IR Echo Spectroscopy. J. Phys. Chem. A 2011, 115, 9731-9738.

(29) Carrion-Vazquez, M.; Oberhauser, A. F.; Fisher, T. E.; Marszalek, P. E.; Li, H.; Fernandez, J. M. Mechanical design of proteins studied by single-molecule force spectroscopy and protein engineering. Prog. Biophys. Mol. Biol. 2000, 74, 63-91.

(30) Chauhan, V. S.; Gupta, M.; Bagaria, A.; Mishra, A.; Mathur, P.; Basu, A.; Ramakumar, S. Self-Assembly of a Dipeptide- Containing Conformationally Restricted Dehydrophenylalanine Residue to Form Ordered Nanotubes. Adv. Mater. 2007, 19, 858-861.

(31) Krysmann, M. J.; Castelletto, V.; Hamley, I. W. Fibrillisation of hydrophobically modified amyloid peptide fragments in an organic solvent. Soft Matter 2007, 3, 1401-1406. 
(32) Castelletto, V.; Gouveia, R. M.; Connon, C. J.; Hamley, I. W. New RGD-peptide amphiphile mixtures containing a negatively charged diluent. Faraday Discuss. 2013, 166, 381-397.

(33) Serpell, L. C. Alzheimer's amyloid fibrils: structure and assembly. Biochim. Biophys. Acta, Mol. Basis Dis. 2000, 1502, 16-30.

(34) Nagy-Smith, K.; Moore, E.; Schneider, J.; Tycko, R. Molecular structure of monomorphic peptide fibrils within a kinetically trapped hydrogel network. Proc. Natl. Acad. Sci. U. S. A. 2015, 112, 98169821.

(35) Decandio, C. C.; Silva, E. R.; Hamley, I. W.; Castelletto, V.; Liberato, M. S.; Oliveira, V. X.; Oliveira, C. L. P.; Alves, W. A. SelfAssembly of a Designed Alternating Arginine/Phenylalanine Oligopeptide. Langmuir 2015, 31, 4513-4523.

(36) Morris, K. L.; Zibaee, S.; Chen, L.; Goedert, M.; Sikorski, P.; Serpell, L. C. The Structure of Cross- $\beta$ Tapes and Tubes Formed by an Octapeptide, $\alpha \mathrm{S} \beta 1$. Angew. Chem., Int. Ed. 2013, 52, 2279-2283.

(37) Kratky, O. G. O. Small angle $x$-ray scattering; Academic Press, 1982; p 515.

(38) Zozulia, O.; Dolan, M. A.; Korendovych, I. V. Catalytic peptide assemblies. Chem. Soc. Rev. 2018, 47, 3621-3639.

(39) Rodríguez-Llansola, F.; Miravet, J. F.; Escuder, B. A supramolecular hydrogel as a reusable heterogeneous catalyst for the direct aldol reaction. Chem. Commun. 2009, 47, 7303-7305.

(40) Rodríguez-Llansola, F.; Escuder, B.; Miravet, J. F. Switchable Perfomance of an L-Proline-Derived Basic Catalyst Controlled by Supramolecular Gelation. J. Am. Chem. Soc. 2009, 131, 11478-11484.

(41) Rodríguez-Llansola, F.; Escuder, B.; Miravet, J. F. Remarkable increase in basicity associated with supramolecular gelation. Org. Biomol. Chem. 2009, 7, 3091-3094.

(42) Singh, N.; Kumar, M.; Miravet, J. F.; Ulijn, R. V.; Escuder, B. Peptide-Based Molecular Hydrogels as Supramolecular Protein Mimics. Chem. - Eur. J. 2017, 23, 981-993.

(43) Kühbeck, D.; Saidulu, G.; Reddy, K. R.; Díaz, D. D. Critical assessment of the efficiency of chitosan biohydrogel beads as recyclable and heterogeneous organocatalyst for C-C bond formation. Green Chem. 2012, 14, 378-392.

(44) Hajos, Z. G.; Parrish, D. R. Asymmetric synthesis of bicyclic intermediates of natural product chemistry. J. Org. Chem. 1974, 39, $1615-1621$.

(45) Eder, U.; Sauer, G.; Wiechert, R. New Type of Asymmetric Cyclization to Optically Active Steroid CD Partial Structures. Angew. Chem., Int. Ed. Engl. 1971, 10, 496-497.

(46) Hajos, Z. G.; Parrish, D. R. Asymmetric synthesis of optically active polycyclic organic compounds. DE 71-21026231971. 1971.

(47) Dalko, P. I. Enantioselective Organocatalysis - Reactions and Experimental Procedures; Wiley-VCH: Weinheim, 2007.

(48) Panday, S. K. Advances in the chemistry of proline and its derivatives: an excellent amino acid with versatile applications in asymmetric synthesis. Tetrahedron: Asymmetry 2011, 22, 1817-1847.

(49) Pochan, D. J.; Schneider, J. P.; Kretsinger, J.; Ozbas, B.; Rajagopal, K.; Haines, L. Thermally Reversible Hydrogels via Intramolecular Folding and Consequent Self-Assembly of a de Novo Designed Peptide. J. Am. Chem. Soc. 2003, 125, 11802-11803.

(50) Sathaye, S.; Zhang, H.; Sonmez, C.; Schneider, J. P.; MacDermaid, C. M.; Von Bargen, C. D.; Saven, J. G.; Pochan, D. J. Engineering Complementary Hydrophobic Interactions to Control $\beta$ Hairpin Peptide Self-Assembly, Network Branching, and Hydrogel Properties. Biomacromolecules 2014, 15, 3891-3900.

(51) Douglas, J. F. Weak and Strong Gels and the Emergence of the Amorphous Solid State. Gels 2018, 4, 19.

(52) Castelletto, V.; Edwards-Gayle, C. J. C.; Hamley, I. W.; Barrett, G.; Seitsonen, J.; Ruokolainen, J. Peptide-Stabilized Emulsions and Gels from an Arginine-Rich Surfactant-like Peptide with Antimicrobial Activity. ACS Appl. Mater. Interfaces 2019, 11, 9893-9903.

(53) Hamley, I. W. Introduction to Soft Matter: Synthetic and Biological Self-Assembling Materials, 2nd ed.; Wiley, 2007; p 342.

(54) Kjøniksen, A.-L.; Nyström, B.; Lindman, B. Dynamic Viscoelasticity of Gelling and Nongelling Aqueous Mixtures of
Ethyl(hydroxyethyl)cellulose and an Ionic Surfactant. Macromolecules 1998, 31, 1852-1858. 